\title{
Street Invading, Forbidding or Instructing: A Case Study of the University Avenue in Shanghai, China
}

\author{
BOLUN WANG
}

Tongji University

This paper engages in a dialectical analysis of street invading, a common phenomenon in China. Taking a specific case in Shanghai, the article tries to figure out the phenomenon's social appearance and understand the essence behind it. Basing on the conceptual framework of "informal," it is easy to find the essence of the phenomenon is informality. From the mechanism of the generation of informality, the paper then analyzes the intrinsic logic behind the street invading through top-down and bottom-up aspects, pointing out that this phenomenon should be understood as a new urban culture. Hence, despite this phenomenon has plenty of deficiencies, we ought not to forbid it all the time (like what the local Chinese government did before). Instead, the article suggests that instructing it in a proper way weighs more important and then introduces the specific measures taken by the local government in this case from both the top-down and bottom-up perspectives. Finally, the paper draws to a conclusion that in face of the street invading, instructing is more important than forbidding and summaries three strategies in how to deal with the similar cases.

\section{INTRODUCTION}

The University Avenue (UA), located in Yangpu district, Shanghai, was built as a main street in the Knowledge and Innovation Community (KIC) since 2004, connecting between an urban arterial and a university campus. The street was flanked by mixed-use live and work buildings, combining residential, commercial and office space. ${ }^{1}$

In 2010, the ground floor commercial activities went through an official upgraded transformation. More food and beverage (F\&B) commercial, heavily occupied by coffee shops and international restaurants, moved into the street. The large amount of retail and F\&B uses includes a number of fitness and informal fashion brands receives about 10,000 visitors a day. ${ }^{1}$ Gradually, merchants enlarged their business scope by putting Café umbrellas and outdoor seating outside the shop, occupying the pavement, in order to attract more visitors.

This phenomenon, as I called street invading, is a common social behavior in China as well as in many other developing countries. Merchants have their own business space, yet they occupy the public space, such as pavement, square etc., in order to have more profitable bargain or service. The behavior brings benefit to merchants, however, it seems that the deficiencies it brings overweigh more than its merits. The outdoor facilities occupy public space and hinder public transportation,

which brings a messy ground circulation. What's more, the outdoor commercial produces noise inevitably, which affects the daily life of locals (a typical case is called Yongkang Road, a bar street located in Shanghai, which has been dismantled last year because of its huge noise at night).

The normal attitude had by local government, in regard to this issue, is forbidding the outdoor facilities. Take the UA for example, the local government adopted several measures for instance oral warning, fining or confiscating. However, the game between administrators and merchants seems a guerrilla: merchants hided their outdoor stuff when the administrator was on duty and put them out again when they left. Apparently, this forbidding strategy failed, like the same situations in many other invaded streets. But why?

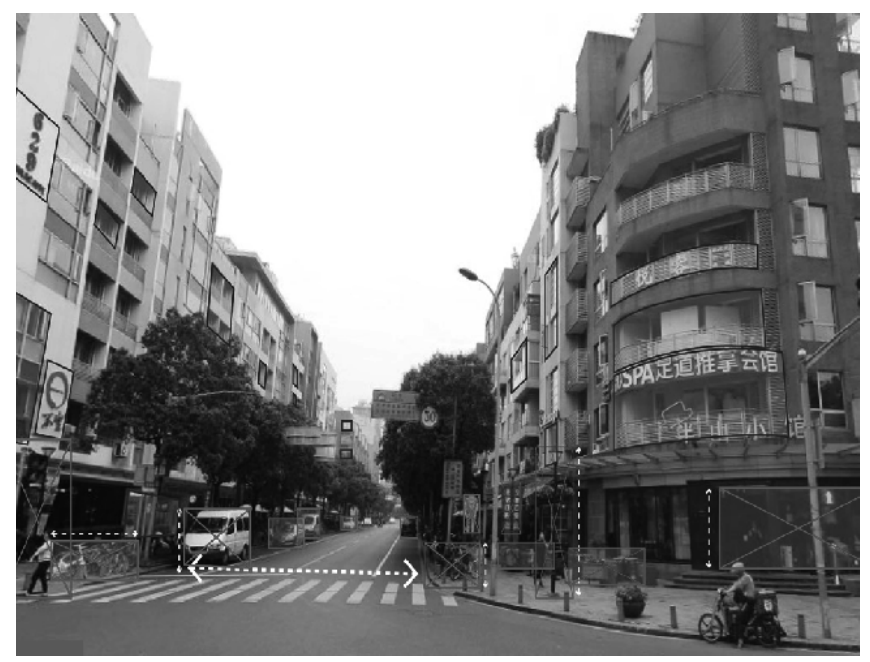

Figure 1: Messy tables and sunshades lying on the sidewalk, disordered parks flanking the street, c.2015, Google Earth, reedited by author.

\section{INTRINSIC LOGIC BEHIND THE STREET INVADING}

Seeing through the appearance to the essence is always important when analyzing a social phenomenon. ${ }^{2}$ From my point of view, the reason why the management failed here: the street invading has its own interior essence under its low-end exterior appearance. However, the government always neglects that and superficially concentrates on its disorderly outside. Forbidding, to some extent, is a way of stopping external informal activities, but not a radical way of solving the problem. Hence, to get clear on this matter, we need to dive into the phenomenon and find out the intrinsic essence behind. 


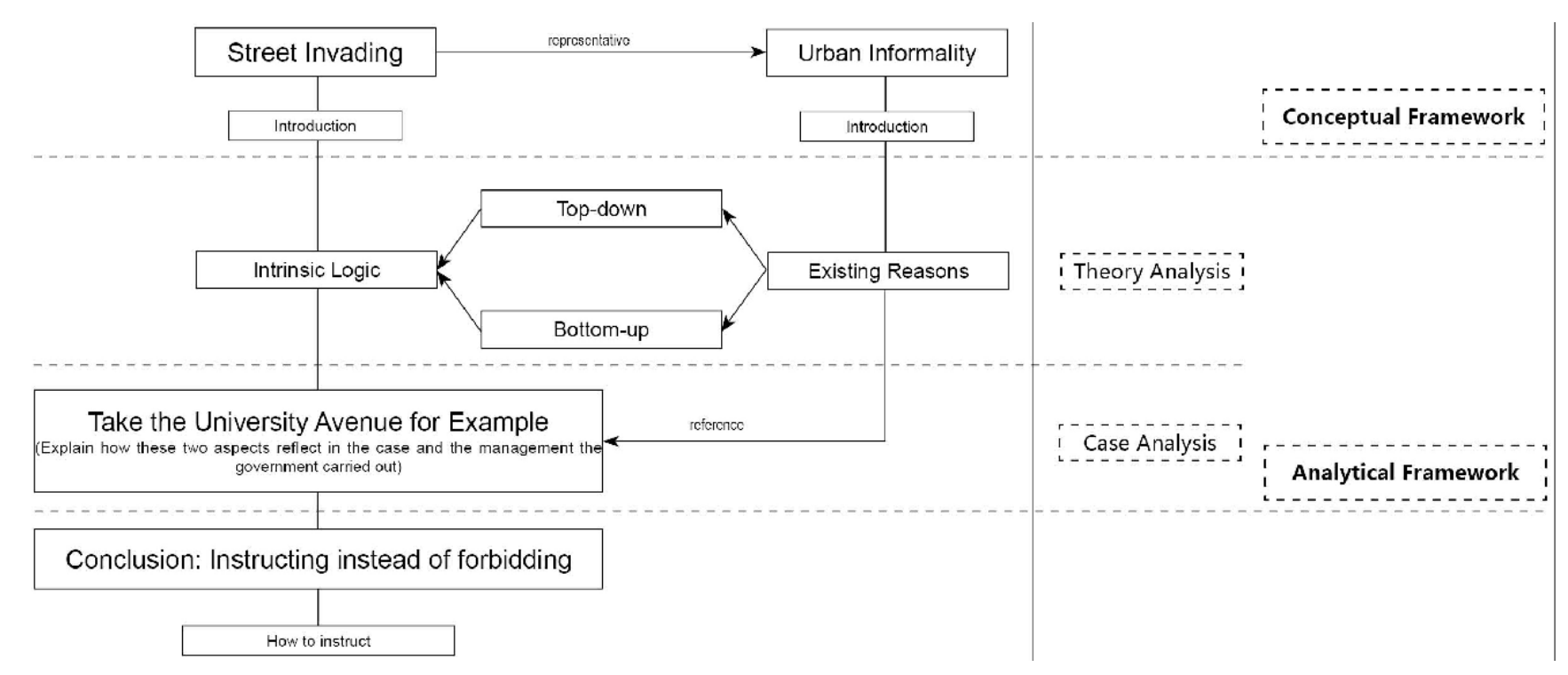

Figure 2: Paper Framework, drawn by author.

In fact, this phenomenon can be seen as a typical representative of urban informality. The urban informality derives from the concept "informal sector" in the early 1970s, referring to the "multitude of people whom one sees thronging the city streets, sidewalks and back alleys in the developing countries." ${ }^{3}$ It is a self-employment rather a wage-earning when comes to the type of employment in informality. ${ }^{4}$ Along with Nezar AlSayyad, Ananya Roy uses the term urban informality to indicate an organizing logic, a system of norms that governs the process of urban transformation itself. ${ }^{5}$ Nowadays it also refers to the spontaneous urbanization that implemented by individuals without any official instructions.

To reach the essence of street invading is to reach the essence of the urban informality. We need to figure out the potential reason leading to the urban informality. It lies in both topdown and bottom-up aspects.

From the perspective of top-down, urban informality comes from the deficiency or slack of the official planning and authority controlling mechanism. ${ }^{6}$ To some extent it generates from the failure of the official social, governmental and economical plan that satisfies the needs of the citizens. However, no city planners have an ideal plan which could cope with all the potential issues happened in unpredicted future. Hence, this managing failure exists inevitably, which in result provides an underlying foundation for the urban informality.

From the perspective of bottom-up, citizens have their subjective initiatives and benefit-seeking psychology. Every citizen has its own demand towards city. When it can't be solved in a formal way, they seek their demands in an informal way, costing the lowest and neglecting its legality. Because of this basic individual economic behavior, the urban informality finds its breeding ground to root. What's more, the potential urban space, such as pavement, square or even rooftop, has both spatial and social conditions of accommodating and developing the urban informality. Take public pavement for example, the blank space of streets provides a commercial bargaining spot and the passersby serve as a role of customers.

As we can see, the urban context has its inherent spontaneity and contingency. Under the deficiency of urban planning, continuous bottom-up construction and reconstruction inevitably occur every day. ${ }^{6}$ The deficiency of the planning, the subjective initiatives and benefit-seeking psychology of citizens, and the potential urban space, all the three inevitable factors indicate that the urban informality has its reasons to exist: it is a survival strategy and a creative reaction to the urban issues, and a valid power to weaken the oppression from bureaucrats and the resist the colonization of daily life. It is an organizing logic which emerges under a paradigm of liberalization. ${ }^{6}$

Hence, the essence of the urban informality is a life style, a development pattern, a city experience and the logic to organize the city, which should be understood as a new urban culture that we should learn and protect. ${ }^{7}$

Looking back on this street invading, we can easily find out its intrinsic logic under the concept framework of the urban informality. From the top-down aspect, the UA government lacked a previous governing plan and operation mechanism in regard to this informal activity. And when this informality happened, administrators only tried to forbid the informal street activities superficially instead of thinking about the mechanism behind and figuring out a suitable strategy.

From the perspective of bottom-up, the merchants in the UA, like any other merchants in the city, pursued a maximization of benefit and had the initiative wills to seek profit at 
the lowest cost. What's more, as an important link between Songhu Road and Fudan University, the UA had a large amount of people passing through every day. The abundant visitors bring a vast commercial consumption, which offers a potential commercial opportunity to the merchants. Besides, the along-street stores with only 4-6 meters depth is not spacious enough for the existing commercial activities, yet the 8 meters wide pavement seems luxurious and not fully-used. In a word, under the lack of management, merchants have their necessity to expand the shops and the street has its possibility to accommodate the expansion. All these three factors promote the merchants gradually occupying the street as an additional bargaining space.

\section{INSTRUCT THE STREET INVADING}

As we concluded, the urban informality has its reasons existing here and we should treat it as an urban culture. However, the street invading, as one representative of the urban informality, indeed has deficiencies. As we talked about before, it results in negative affect on street environment and noise problem. Therefore, we have a pressing need to instruct it in a formal way based on its logic behind.

Fortunately, the government realized the potential reason and altered their mind from forbidding to instructing in these years. Firstly, from the top-down perspective, the government transferred its attitude towards the informality from suppression to instruction. An innovated managing mechanism called "Responsible Management" had been carried out in order to standardize the street in an over situ-

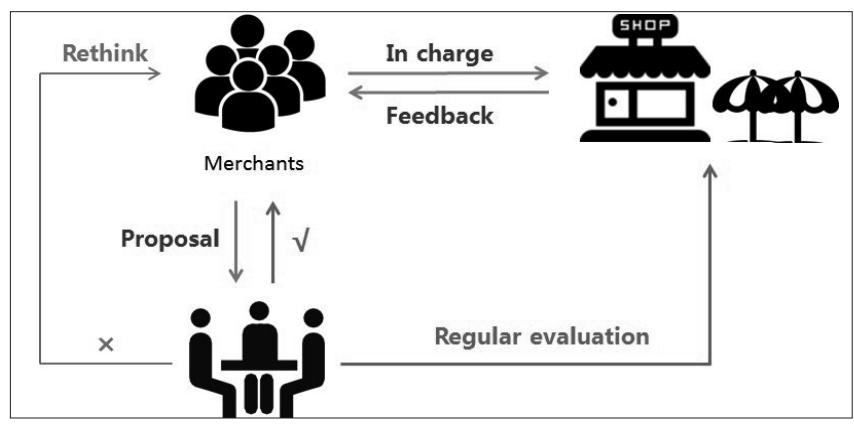

Figure 3: "Responsible Management" System in UA, drawn by author.

ation. It included an "Outdoor Café Seating" strategy and a "Delicacy Management," which to some extent permits the shop extensions. ${ }^{8}$ However, the merchants were requested to offer an elaborate plan concerning how they managed the outdoor facilities and to accept an annual check. The serving time and the scope of the outdoor commercial are also strictly stipulated. Any shops which break the regulations will be punished or even be expelled out of the street. These managements filled the previous governing blank and in result brought a neat order.
From the perspective of bottom-up, the citizens' subjective initiative and benefit-seeking psychology were accepted and instructed by government under the new managing mechanism. The government loosed the authority and inspired the local to govern themselves by organizing a self-governing group among both merchants and citizens. At the same time, "Co-organized" system has been introduced, where citizens and governors could meet and discuss. In this way, the peoples' demand has been considered officially and their initiative has been well controlled in case it expanded extremely. What's more, the pavement space also was redesigned into three zones: outdoor-seating zone, pedestrian zone and facility zone, in order to make the street more efficiently using in a well-organized way. ${ }^{9}$

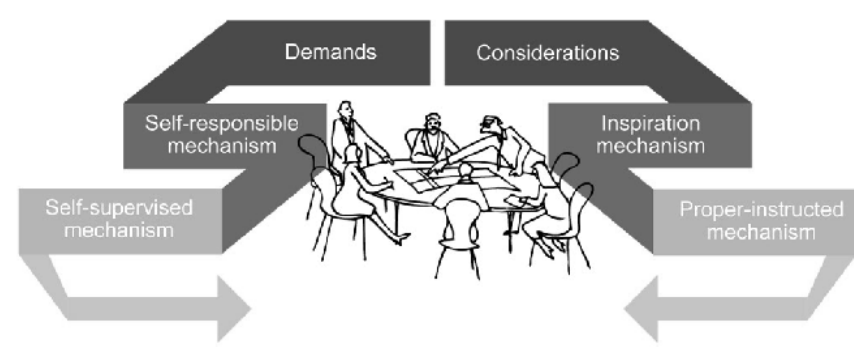

Figure 4: "Co-organized" System Has Been Introduced, reedited by author.

The new strategies bring a positive result. On one hand because of the standardization of informality management that could be relied on, merchants have to rethink about the outdoor stuff and reorganize them in an orderly way, which in result brings a nice clean street environment. On the other hand, due to the legalization of informality activities, merchants are relieved, having no anxiety on being fined or other punishment and willing to improve their outdoor commercial activities to offer a better service, which, as a result, attracts more visitors. The increasing people not only bring the street more vitality, but also improve the street's fame in Shanghai, which provides the street a virtuous circled development.

\section{CONCLUSION: INSTRUCTING INSTEAD OF FORBIDDING}

We can easily draw a conclusion from the success of the UA. The street invading, as one representative of the urban informality, has its own mechanism. As far as I see, the intrinsic logic urban informality appears under a specific given context, and the "informal" way may be the only possible way of urbanization when no other options exist. As a result, we should take the street invading as an urban strategy and culture. Hence, forbidding all the time is not a radical management. Instead, understanding its specific forming context as well as logic, and instructing it to a formal urbanization overweighs more important.

To instruct the street invading, I summarized the " 31 " strategies based on the UA case. 


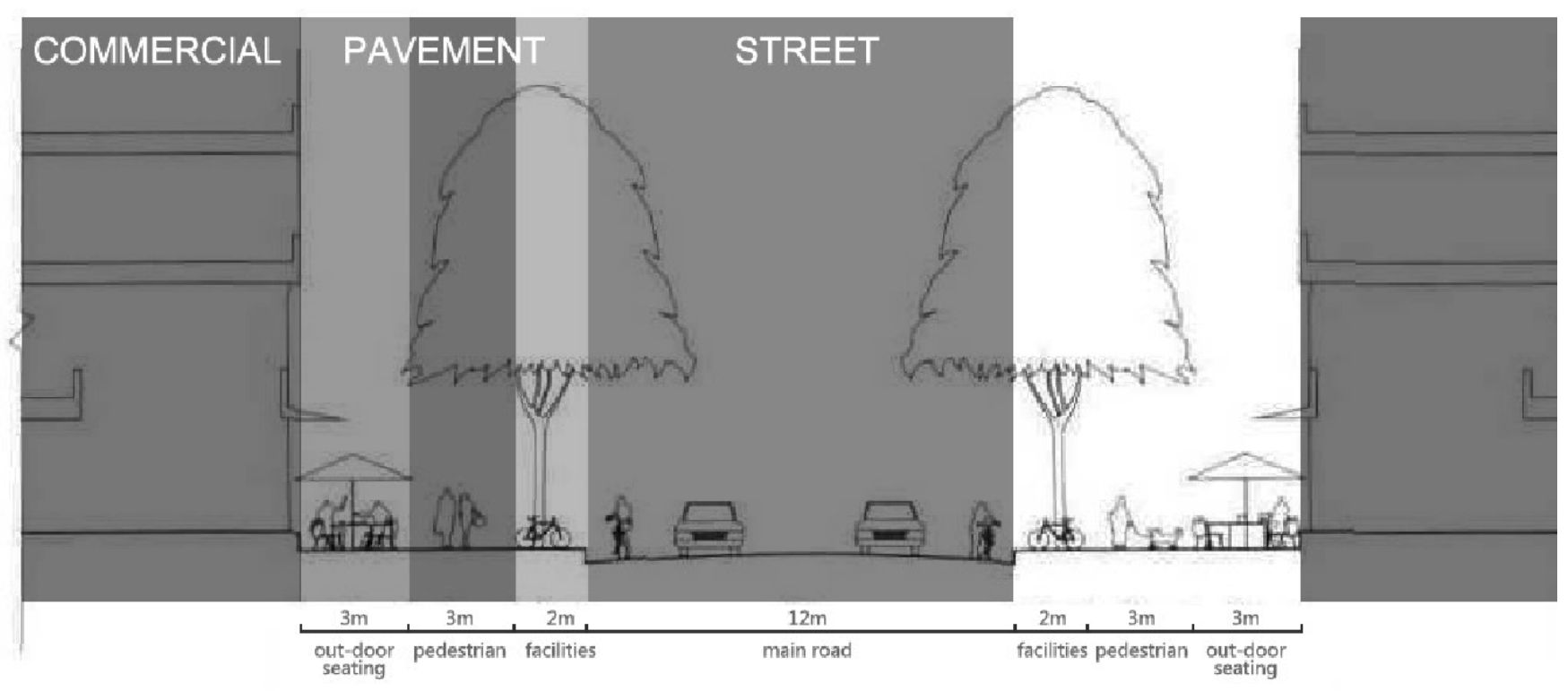

Figure 5: The Redesigned Street Section, Chen Qian, reedited by author.

\section{(1) Identification}

- Street invading is a spontaneous phenomenon deriving from a given urban context. Hence we should identify the specific context in which this urban spontaneity happens: What kind of the management lacks there? What subjective demands have the locals there? What the objective spatial condition provides there and so on.

(2) Instruction

- Then, when fully understand the circumstance, government should adjust measures to the identifications and instruct the locals in a way of neither breaking the existing social relations nor sacrificing the street order, such as carrying out the "Responsible Instruction," "Delicacy Instruction" in the UA case.

(3) Inspiration

- In the end, when the new management settles, the government should inspire merchants' self-discipline and form their own autonomous group by encouragement policy, in order to supervise and maintain the area themselves in a sustainable way.

Nowadays, the UA has become one of the most attractive streets in Shanghai, due to its successful management. However, a number of invaded streets are still suffering the government's forbidding policy. I hope this article could be enlightenment to the local government and drive them to rethink of the management towards the street invading: Instructing overweighs more than forbidding.

\section{ENDNOTES}

1. "Knowledge and innovation community," ULI case studies, https://casestudies.uli.org/knowledge-and-innovation-community-shanghai/.

2. Karl Heinrich Marx, Das Kapital. (Beijing: People's Publishing House, 2004), 32.

3. LG. Reynolds, "Economic Development with Unlimited Supplies of Labor, Some Complications," Oxford Economic Papers 21, no.1 (1969), 91.

4. Keith Hart, "Informal Income Opportunities and Urban Employment in Ghana," Modern African Studies II, no.1 (1973), 61-89.

5. Ananya Roy \& Nezar AlSayyad, Urban informality: Transnational perspectivesfrom the Middle East, South Asia and Latin America. (Lanham, MD: Lexington Books, 2004), 289-317.

6. Long Yuan, "Hanzhengjie: An Informal City," Times + Architecture, no. 3 (2006), 136-141.

7. Ananya Roy, "Urban informality: Toward an Epistemology of Planning," Journal of the American Planning Association , no. 2 (2005),147-158.

8. Jin Wensi, "Could the Outdoor-seating in University Avenue Be Generalized to Other Road," Xin Min Daily Newspaper, 5 November 2016, p.9.

9. Qian Chen, "Implications of the 10-year Daxue Road Evolution on Street Revival," Times + Architecture, no. 6(2017), 55-61. 